\section{Characterisation of the microflora contaminating the wooden vats used for traditional Sicilian cheese production}

\author{
Maria Luisa Scatassa, ${ }^{1}$ \\ Cinzia Cardamone, ${ }^{1}$ Viviana Miraglia, ${ }^{1}$ \\ Fabrizio Lazzara, ${ }^{1}$ Gerlando Fiorenza, ${ }^{1}$ \\ Giusi Macaluso, ${ }^{1}$ Luigi Arcuri, ${ }^{2}$ \\ Luca Settanni, ${ }^{3}$ Isabella Mancuso ${ }^{1}$ \\ 1'Institute for Experimental Veterinary \\ Medicine of Sicily A. Mirri, Palermo; \\ ${ }^{2}$ Local Health Unit 6, Palermo; \\ ${ }^{3}$ Department of Agricultural and Forest \\ Sciences, University of Palermo, Sicily
}

\begin{abstract}
Traditional Sicilian cheese productions are carried out employing traditional wooden vats, called tina. Many studies have highlighted the beneficial role of wooden dairy equipment by contributing to enriching the milk microflora and improving the acidification processes. The present work was undertaken to evaluate the safety of the wooden vats used to coagulate milk. To this purpose, the different microbial populations hosted onto the internal surfaces of the vats used to produce two different stretched cheeses, namely Caciocavallo Palermitano and Vastedda della valle del Belice $D O P$, were investigated for the presence of spoilage and pathogenic microorganisms as well as for bacteria with inhibitory effect in vitro against pathogenic microorganisms. A wide biodiversity of protechnological lactic acid bacteria (LAB), in terms of species, was revealed. Several LAB inhibited the growth of Listeria monocytogenes ATCC 7644. The wooden vats analysed resulted safe for three main findings: absence of the main pathogenic species, presence of high levels of $\mathrm{LAB}$, antiListeria activity of many LAB.
\end{abstract}

\section{Introduction}

Bovine and ovine Sicilian farms have traditionally produced raw milk cheeses, using different wooden equipment consisting of: tina, a truncated conical flat base 200-400 L container for milk coagulation; rotula, an about $20 \mathrm{~cm}$ long stick with a terminal disc used for breaking the curd; piddiaturi, an about $50 \mathrm{~L}$ washtub where the stretching is performed; and tavuleri, a rectangular container where Caciocavallo Palermitano assumes its characteristic parallelepiped shape (Figure 1).
The possibility offered by the $92 / 46$ CEE Directive, implemented by the 54/97 DPR, to derogate the hygiene requirements of traditional cheeses production equipment, induced the Sicilian Region to identify the traditional dairy products by the $4492 / 98$ Decree of the Sicilian Region. To allow the derogation application, the decree briefly describes each cheese production processes and the corresponding wooden equipment, which normally could not be used because of the porous material that does not allow an effective cleaning and sanitation.

The current Regulation 852/2004 of the European Community (European Commission, 2004) on food hygiene allows the use of any type of equipment as long as food business operators are able to demonstrate they are made with materials ensuring the safety of the final product. Sicilian cheese makers have traditionally managed wooden vat hygiene through washing of this container with the hot deprotenised whey resulting from the production of ricotta cheese and/or hot water, sometimes with a careful brushing, leaving the wooden vat full with the whey for about $12 \mathrm{~h}$. These operations tend to empirically regulate, also according to the environmental temperatures, the so-called tina acidity, influencing the microbial composition on the vat inner surface, that is in direct contact with the milk.

Some studies have shown that the wooden vats used for raw milk cheese production allows the development of a biofilm on the inner surface which actively participates in the production process (Lortal et al., 2008; Didienne et al., 2012; Settanni et al., 2012).

In this study, we evaluated the wooden vats used for the production processes of Caciocavallo Palermitano cheese, a bovine raw milk pasta filata cheese with 3 to 18 months ripening, and Vastedda della valle del Belice $D O P$, a fresh sheep raw milk pasta filata cheese. The aim of the study was to determine the presence of spoilage and pathogenic microorganisms, to evaluate the species composition of the lactic acid bacteria (LAB) hosted onto the inner surfaces of the wooden vats, and to investigate on their in vitro antibacterial effect.

\section{Materials and Methods}

In this study, the wooden vats of 12 dairy factories of western Sicily were microbiologically investigated. Eight factories, all located within the Palermo province, produce Caciocavallo Palermitano (CP) cheese, while the other 4 factories produce Vastedda della valle del Belice DOP (VB) cheese in the production area of the provinces of Agrigento and Trapani. The analyses were carried out during two consecutive production years. A total of 20 wooden vats
Correspondence: Maria Luisa Scatassa, Institute for Experimental Veterinary Medicine of Sicily A. Mirri, via Gino Marinuzzi 3, 90129 Palermo, Italy. Tel. +39.091.6565300 - Fax: +39.091.6565332.

E-mail: luisa.scatassa@izssicilia.it

Key words: Wooden vat, Biofilm, Sicilian cheese, Inhibitory activity, Food safety.

Conflict of interests: the authors declare no potential conflict of interests.

Funding: this work was supported by the Italian Ministry of Health Research Project RC 06-2011 Prodotti lattiero caseari tradizionali Siciliani: tecniche di produzione e rischio microbiologico.

Acknowledgments: the authors would like to thank A. Carrozzo and B. Ducato for their precious collaboration.

Received for publication: 7 July 2014.

Revision received: 13 November 2014

Accepted for publication: 14 November 2014.

This work is licensed under a Creative Commons Attribution 3.0 License (by-nc 3.0).

(C) Copyright M.L. Scatassa et al., 2015

Licensee PAGEPress, Italy

Italian Journal of Food Safety 2015; 4:4509

doi:10.4081/ijfs.2015.4509

(13 used for CP cheese production and made of chestnut wood and 7 used for VB cheese and made of Douglas fir) were sampled.

The biofilms were collected for the investigation of total mesophilic count (TMC), lactic acid populations and hygiene indicator bacteria from the inside of the vats by brushing a $100 \mathrm{~cm}^{2}$ area, delimited with a $10 \times 10 \mathrm{~cm}$ sterile plastic mask $\left(80 \mathrm{~cm}^{2}\right.$ from the bottom and $20 \mathrm{~cm}^{2}$ from the side surface) with a sterile brush moistened with a transport medium (buffered peptone water, BPW). The same surface, was then cleaned with a sterile gauze (Figure 2). Both brush and gauze were aseptically transferred in BPW, kept refrigerated during transport by a portable fridge. The search of Listeria monocytogenes and Salmonella spp. was performed on a larger surface area, 400 $\mathrm{cm}^{2}$, using a $20 \times 20 \mathrm{~cm}$ mask.

All the samples were analysed to determine the following microbiological counts: TMC at $30^{\circ} \mathrm{C}$ on Plate Count Agar (PCA) - 0xoid (Basingstoke, UK) incubated at $30^{\circ} \mathrm{C}$ for $72 \mathrm{~h}$ (ISO 4833:2003; ISO, 2003b), sulphite reducing anaerobes on Iron Sulphite Agar - 0xoid, incubated at $37^{\circ} \mathrm{C}$ for $24 \mathrm{~h}$ (ISO 15213:2003; ISO, 2003c), coliforms on Violet Red Bile agar (VRBA) - Oxoid, incubated at $37^{\circ} \mathrm{C}$ for $24 \mathrm{~h}$ (ISO 4832:2006; ISO, 2006), enterococci on Rapid Enterococcus Agar (REA) - Biorad (Hercules, CA, USA) incubated at $44^{\circ} \mathrm{C}$ for $48 \mathrm{~h}$ and confirmation of suspected colonies by 
microscopic examination, catalase testing (Fluka, St. Gallen, Switzerland) and detection on Bile esculina agar (0xoid), Escherichia coli on Tryptone Bile Glucuronide Agar-0xoid incubated at $44^{\circ} \mathrm{C}$ for $24 \mathrm{~h}$ (ISO 16649-2:2001; ISO, 2001) and coagulase positive staphylococci on Baird Parker (BP) with added RPF supplement-0xoid, incubated at $37^{\circ} \mathrm{C}$ for $24 \mathrm{~h}$ (ISO 6888-2: 1999 Amend 1:2003; ISO, 2003a).

Listeria monocytogenes investigation was performed by using the enzyme immunoassay ELFA (Enzyme Linked Fluorescent Assay) instrument VIDAS (bioMerieux, Marcy-l'Etoile, France). Salmonella spp was detected using the AFNOR BIO 12/23-05/07 method with a preenrichment in Buffered Peptone Water incubated at $37^{\circ} \mathrm{C}$ for for $16-20 \mathrm{~h}$ followed by subculture in Xylose Lysine Deoxycholate (XLD) Agar (Oxoid) and Brillant Green Agar (Oxoid) at $37^{\circ} \mathrm{C}$ for $20-24$ h. Listeria monocytogenes was detected using the AFNOR BIO 12/11-03/04 with a pre-enrichment in Half Fraser broth (Oxoid) incubated at $30^{\circ} \mathrm{C}$ for $24-26 \mathrm{~h}$ and subsequent culture on Fraser broth (FB) (Oxoid) incubated at $37^{\circ} \mathrm{C}$ for $24-26 \mathrm{~h}$. An aliquot of FB is used to perform the VIDAS LMO2 test (bioMerieux).

Lactic acid bacteria were counted and isolated by using the ISTISAN 08/36 Reports: mesophilic and thermophilic cocci were plated on $\mathrm{M} 17$ agar incubated at $30^{\circ} \mathrm{C}$ for $72 \mathrm{~h}$ and $44^{\circ} \mathrm{C}$ for $48 \mathrm{~h}$, respectively; mesophilic lactobacilli were isolated by using MRS agar $(\mathrm{pH}$ 5.4) incubated anaerobically at $37^{\circ} \mathrm{C}$ for $72 \mathrm{~h}$.

Lactic acid bacteria isolates were genetically identified by $16 \mathrm{~S}$ rRNA gene sequencing. The DNA was extracted by the Instagene Matrix (Biorad) according to the manufcturer's instructions. PCRs were performed as described by Weisburg et al. (1991) using the primers rD1 (5'-AAGGAGGTGATCCAGCC-3') and fD1 (5'-AGAGTTTGATCCTGGCTCAG-3') and the AmpliTaq Gold ${ }^{\circledR} 360$ DNA Polymerase (Life Technologies, Carlsbad, CA, USA). DNA sequences were determinated by using an $\mathrm{ABI}$ PRISM 3130 Genetic Analyzer (Applied Biosystems, Carlsbad, CA, USA) and compared using a BLAST search in the GenBank/ EMBL/DDBJ database (http://www.ncbi.nlm. nih.gov). The isolates were considered to represent a given species when a $97 \%$ or higher similarity was detected.

For the in vitro antibacterial activity assay, $\mathrm{LAB}$ isolates were tested using the spot on the lawn method, which shows the inhibitory activity against target microorganisms, by the detection of an inhibition halo around the colony strain tested (Patriarca et al., 2012). The following bacteria sensitive to the inhibitory activity of LAB were used as indicators: L. monocytogenes ATCC 7644, E. coli ATCC 25922, Salmonella enteritidis ATCC 13076 and Staphylococcus aureus ATCC 25923.

The strains cryopreserved at $-80^{\circ} \mathrm{C}$ were revitalised in $5 \mathrm{~mL}$ of MRS broth at $37^{\circ} \mathrm{C}$ for $72 \mathrm{~h}$ in the presence of $\mathrm{CO}_{2}$. Petri plates containing Tryptone Soya Agar (TSA) plus $0.5 \%$ of yeast extract were spotted with $2 \mu \mathrm{L}$ of each culture broth and incubated anaerobically overnight at $30^{\circ} \mathrm{C}$. Brain Heart Infusion (BHI; Difco) containing $1 \%$ agar was tempered to $45^{\circ} \mathrm{C}$ and seeded with $10^{5}-10^{6} \mathrm{CFU} / \mathrm{mL}$ of each pathogen. The spotted plates were overlaid with $8 \mathrm{~mL}$ of the seeded BHI agar and then incubated at $30^{\circ} \mathrm{C}$ in anaerobiosis for $24 \mathrm{~h}$. Inhibition was detected by a zone of clearing (>3 mm) around the producer colony (Patriarca et al., 2012).

Table 1. Microbial groups detected in the vats used for Caciocavallo Palermitano cheese production $\left(\log \mathrm{CFU} / \mathrm{cm}^{2}\right)$.

\begin{tabular}{lcccc} 
& Mean & Min & Max & SD \\
TMC & 5.26 & 3.62 & 6.95 & 0.91 \\
Mesophilic LAB cocci & 5.38 & 4.00 & 6.48 & 0.63 \\
\hline Thermophilic LAB cocci & 5.81 & 5.15 & 7.43 & 0.71 \\
LAB rods & 4.52 & 3.48 & 5.96 & 0.82 \\
\hline Enterococci & 1.95 & 0.70 & 3.15 & 0.75 \\
Total coliforms & 1.77 & 0.30 & 3.18 & 1.07 \\
\hline E. coli & 1.66 & 0.30 & 2.46 & 0.94 \\
\hline
\end{tabular}

TMC, total mesophilic count; LAB, lactic acid bacteria.
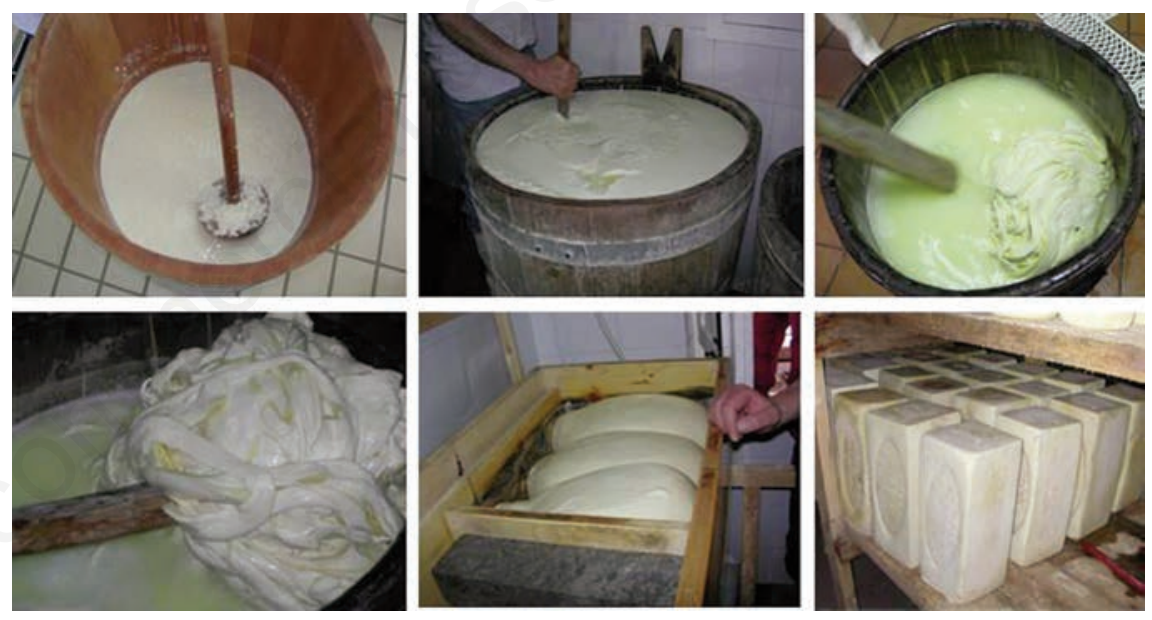

Figure 1. Wooden equipment used for Caciocavallo Palermitano cheese production.
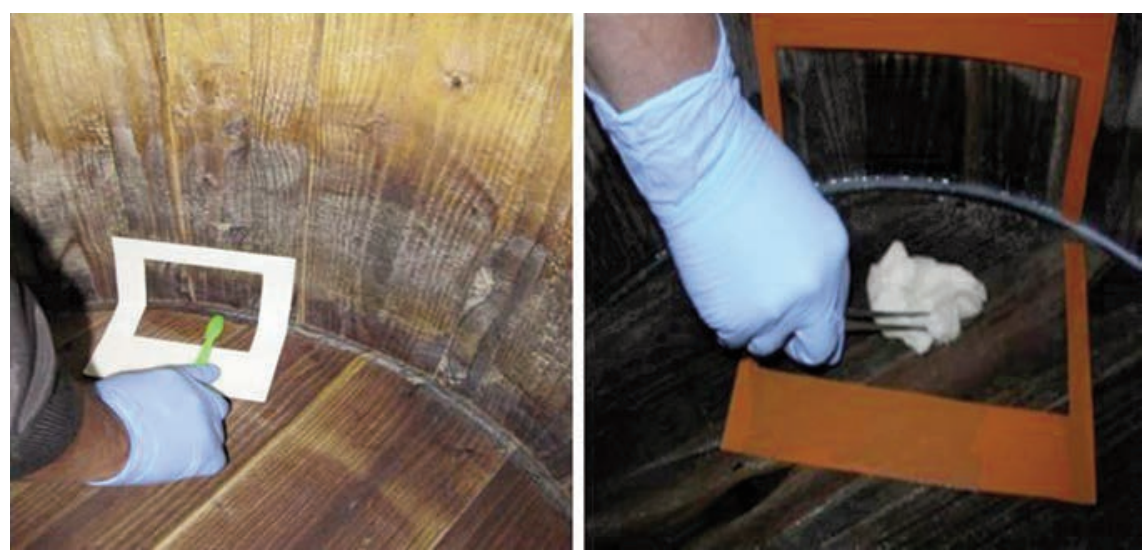

Figure 2. Sampling on the wooden vat surfaces. 
LAB isolated from the VB vats and of $55.7 \%$ for those isolated from the CP vats. The LAB did not show inhibition against the other bacteriocin-sensitive bacteria tested.

The data obtained, expressed as mean values, are reported in Tables 1 and 2. Total mesophilic count and mesophilic LAB cocci were between 3.62 and $6.95 \mathrm{Log} \mathrm{CFU} / \mathrm{cm}^{2}$, while thermophilic LAB cocci were slightly higher (3.57 - $7.43 \mathrm{Log} \mathrm{CFU} / \mathrm{cm}^{2}$ ), especially in $\mathrm{CP}$ vats. Total coliforms were detected in 16 wooden vats: 5 of these showed concentrations $<1$ Log $\mathrm{CFU} / \mathrm{cm}^{2}, 10$ between 1.04 and $3.18 \mathrm{Log}$ $\mathrm{CFU} / \mathrm{cm}^{2}$ and only one $6.04 \mathrm{Log} \mathrm{CFU} / \mathrm{cm}^{2}$. Five wooden vats showed $E$. coli concentrations between 0.30 and $2.46 \mathrm{Log} \mathrm{CFU} / \mathrm{cm}^{2}$; only in the farm where the coliforms were highly present, E. coli resulted $3.18 \mathrm{Log} \mathrm{CFU} / \mathrm{cm}^{2}$. In 11 wooden vats, enterococci ranged from $0.70 \mathrm{Log}$ and $3.40 \mathrm{Log} \mathrm{CFU} / \mathrm{cm}^{2}$. In all the samples coagulase-positive staphylococci, $L$. monocytogenes and Salmonella spp. were absent.

The LAB isolated from the $\mathrm{CP}$ vats showed a predominance of Lactobacillus casei, Enterococcus faecium, Lactobacillus rhamnosus, Streptococcus thermophilus and Pediococcus acidilactici (Table 3). The LAB isolated from the VB vats revealed the predominance of two species: Enterococcus faecium and Lactobacillus casei. The percentage of lactic acid strains able to inhibit the growth of $L$. monocytogenes ATCC 7644 was $66.7 \%$ for the et al., 2007; Lortal et al., 2008; Settanni et al.,

The data obtained from this study confirmed the inner surface of the wooden vats used for the presence of a certain species diversity on cheese production ( $\left.\log \mathrm{CFU} / \mathrm{cm}^{2}\right)$.

TMC, total mesophilic count; LAB, lactic acid bacteria.
2012). The LAB isolated from the $C P$ vats showed a predominance of Lactobacillus casei, Enterococcus faecium, Lactobacillus rhamnosus, Streptococcus thermophilus and Pediococcus acidilactici, while in those used for the production of a similar cheese, the Ragusano, a predominance of Streptococcus thermophilus and the absence of Enterococcus faecium was detected. Data on indicator microorganisms (coliforms and E. coli) showed the efficacy of the sanitation procedures applied during cheese production. Only in one case, the presence of high total coliforms loads (6.04 $\mathrm{Log} \mathrm{CFU} / \mathrm{cm}^{2}$ ) and $E$. coli (3.18 $\mathrm{Log} \mathrm{CFU} / \mathrm{cm}^{2}$ ) indicated the need of

Table 2. Microbial groups detected in the vats used for Vastedda della valle del Belice

\begin{tabular}{lcccc} 
& Mean & Min & Max & SD \\
TMC & 5.20 & 3.60 & 6.85 & 1.17 \\
Mesophilic LAB cocci & 5.02 & 4.15 & 6.60 & 0.91 \\
\hline Thermophilic LAB cocci & 4.57 & 3.57 & 6.64 & 1.06 \\
LAB rods & 3.77 & 2.60 & 6.30 & 1.39 \\
\hline Enterococci & 2.40 & 1.65 & 3.40 & 0.80 \\
Total coliforms & 2.30 & 0.60 & 6.04 & 2.04 \\
\hline E. coli & 1.75 & 0.30 & 3.18 & 1.44 \\
\hline
\end{tabular}

Table 3. Lactic acid bacteria strains isolated from the wooden vats and strains with inhibitory activity vs L. monocytogenes ATCC 7644.

\begin{tabular}{|c|c|c|c|c|}
\hline \multirow[t]{2}{*}{ LAB } & \multicolumn{2}{|c|}{ CP vats } & \multicolumn{2}{|c|}{ VB vats } \\
\hline & Isolates (n) & $\begin{array}{c}\text { Inhibitory substance } \\
\text { producer (n) }\end{array}$ & Isolates (n) & $\begin{array}{l}\text { Inhibitory substance } \\
\text { producer (n) }\end{array}$ \\
\hline Enterococcus faecalis & 5 & 3 & 1 & 0 \\
\hline Enterococcus faecium & 12 & 10 & 15 & 14 \\
\hline Enterococcus hirae & 0 & 0 & 2 & 1 \\
\hline Enterococcus spp. & 3 & 0 & 1 & 1 \\
\hline Lactobacillus brevis & 1 & 1 & 4 & 3 \\
\hline Lactobacillus casei & 13 & 2 & 10 & 2 \\
\hline Lactobacillus delbrueckii & 1 & 0 & 2 & 2 \\
\hline Lactobacillus fermentum & 0 & 0 & 2 & 2 \\
\hline Lactobacillus rhamnosus & 11 & 9 & 1 & 0 \\
\hline Lactococcus lactis & 2 & 2 & 1 & 0 \\
\hline Lactococcus lactis subsp. cremoris & 4 & 3 & 0 & 0 \\
\hline Leuconostoc lactis & 1 & 1 & 0 & 0 \\
\hline Leuconostoc mesenteroides & 1 & 0 & 0 & 0 \\
\hline Leuconostoc pseudomesenteroides & 1 & 1 & 0 & 0 \\
\hline Pediococcus acidilactici & 7 & 3 & 4 & 4 \\
\hline Pediococcus lolii & 5 & 2 & 0 & 0 \\
\hline Pediococcus pentosaceus & 2 & 1 & 0 & 0 \\
\hline Streptococcus macedonicus & 2 & 1 & 4 & 4 \\
\hline Streptococcus thermophilus & 8 & 5 & 4 & 1 \\
\hline Total & 79 & $44(55.7 \%)$ & 51 & $34(66.7 \%)$ \\
\hline
\end{tabular}

$\mathrm{CP}$, Caciocavallo Palermitano; VB, Vastedda della valle del Belice DOP; LAB, lactic acid bacteria. 
revising this process.

Probably the biofilm composition might be affected by the characteristics of the milk used, the specific production processes of the two cheeses studied and the wooden vat sanitation procedures. The presence of more than $50 \%$ of the LAB isolates with inhibitory activity vs. L. monocytogenes ATCC 7644 constitutes an additional positive feature, although it must be evaluated in relation to the type of the cheese produced, because traditional Sicilian raw milk cheeses are not commonly subjected to $L$. monocytogenes contamination, as observed in previous studies (Scatassa et al., 2009).

\section{Conclusions}

The correct maintenance of wooden vats, as part of good manufacturing practices of the Caciocavallo Palermitano and the Vastedda della valle del Belice DOP cheese production, promotes the selection of a microbial flora able to play an active role in the achievement of the food safety objectives through the biocompetitive activity of LAB and the inhibitory activity against pathogenic bacteria, particularly $L$. monocytogenes.

\section{References}

Didienne R, Defargues C, Callon C, Meylheuc T, Hulin S, Montel MC, 2012. Characteristics of microbial biofilm on wooden vats ('gerles') in PDO Salers cheese. Int J Food Microbiol 156:91-101.

European Commission, 2004. Regulation of the European Parliament and of the council of 29 April 2004 on the hygiene of foodstuffs, 852/2004/EC. In: Official Journal, L 139/1, 30/04/2004.

IS0, 2001. Microbiology of food and animal feeding stuffs. Horizontal method for the enumeration of beta-glucuronidase-positive Escherichia coli. Part 2: Colony-count technique at 44 degrees $\mathrm{C}$ using 5-bromo4-chloro-3-indolyl beta-D-glucuronide. ISO Norm 16649-2:2001. International Standardization Organization ed., Geneva, Switzerland.

ISO, 2003a. Microbiology of food and animal feeding stuffs. Horizontal method for the enumeration of coagulase-positive staphylococci (Staphylococcus aureus and other species). Part 2: Technique using rabbit plasma fibrinogen agar medium AMENDMENT 1: Inclusion of precision data

IS0, 2003b. Microbiology of food and animal feeding stuffs. Horizontal method for the enumeration of microorganisms. Colonycount technique at 30 degrees C. ISO Norm 4833:2003. International Standardization Organization ed., Geneva, Switzerland.

ISO, 2003c. Microbiology of food and animal feeding stuffs. Horizontal method for the enumeration of sulfite-reducing bacteria growing under anaerobic conditions. ISO Norm 15213:2003. International Standardization Organization ed., Geneva, Switzerland.

ISO, 2006. Microbiology of food and animal feeding stuffs. Horizontal method for the enumeration of coliforms. Colony-count technique. ISO Norm 4832:2006. International Standardization Organization ed., Geneva, Switzerland.
Licitra G, Ogier JC, Parayre S, Pediliggieri C, Carnemolla TM, Falentin H, Madec MN, Carpino S, Lortal S, 2007. Variability of bacteria biofilms of the "Tina" wood vats used in the Ragusano cheese-making process. Appl Environ Microb 73:6980-87.

Lortal S, Di Blasi A, Madec MN, Pediliggieri C, Tuminello L, Tanguy G, Fauguant J, Lecuona Y, Campo P, Carpino S, Licitra G, 2009. Tina wooden vat biofilm: a safe and highly efficient lactic acid bacteria delivering system in PDO Ragusano cheese making. Int J Food Microbiol 132:1-8.

Patriarca V, Di Bartolo I, Tozzoli R, Agrimi U, 2012. Valutazione dell'attività antibatterica delle batteriocine nei confronti di patogeni alimentari. In: Fiore A, Vilmercati A, Anniballi F, De Medici D, eds. Argomenti di Sanità Pubblica Veterinaria e Sicurezza Alimentare. Seminari dipartimentali 2011. Istituto Superiore di Sanità, Rome, Italy, pp 28-35.

Scatassa ML, Di Noto AM, Cardamone C, Sciortino S, Todaro M, Caracappa S, 2009. Vastedda della valle del Belìce cheese: experimental contamination with Salmonella and Listeria spp. Proceedings of XVII FeMESPRum International Congress, pp 298-99.

Settanni L, Di Grigoli A, Tornambè G, Bellina V, Francesca N, Moschetti G, Bonanno A, 2012. Persistence of wild Streptococcus thermophilus strains on wooden vat and during the manufacture of a traditional Caciocavallo type cheese. Int J Food Microbiol 155:73-81.

Weisburg W, Barns SM, Pelletier DA, Lane DJ, 1991. 16S ribosomal DNA amplification for phylogenetic study. J Bacteriol 173:697703. 